\section{Proposta sobre uso de dados de receitas de antimicrobianos retidas: a experiência EUREQA}

\author{
A proposal for using data from antimicrobial \\ prescriptions: the EUREQA experience
}

\author{
${ }^{1}$ Instituto Nacional de \\ Pesquisas Espaciais, São José \\ dos Campos, Brasil. \\ 2 Escola Paulista de \\ Medicina, Universidade \\ Federal de São Paulo, São \\ Paulo, Brasil. \\ ${ }^{3}$ Laboratório de Estatística e \\ Geoinformação, Universidade \\ Federal do Paraná, Curitiba, \\ Brasil. \\ Correspondência \\ E. C. G. Camargo \\ Instituto Nacional de \\ Pesquisas Espaciais. \\ Av. dos Astronautas 1758, \\ São José dos Campos, SP \\ 12227-010, Brasil. \\ eduardo@dpi.inpe.br
}

\section{Abstract}

This study demonstrates that the use of information from medical prescriptions is essential for understanding the dynamics of community bacterial resistance. The resulting analysis can also influence and help establish more adequate public health policies on the control and optimization of antimicrobial use. The article demonstrates the use of a logical model developed by the EUREQA project for acquisition, classification, interpretation, and analysis of data from prescriptions for oral antimicrobial use.

Drug Prescriptions; Anti-bacterial Agents; Microbial Drug Resistance

\author{
Eduardo Celso Gerbi Camargo 1 \\ Carlos Roberto Veiga Kiffer 2 \\ Antonio Carlos Campos Pignatari 2 \\ Silvia Emiko Shimakura 3 \\ Paulo Justiniano Ribeiro Jr. 3 \\ Antonio Miguel Vieira Monteiro ${ }^{1}$
}

\section{Introdução}

O uso das informações sobre prescrições médicas tem importância fundamental em estratégias de saúde pública. Em particular, informações de antimicrobianos poderiam possibilitar a construção de modelos para a compreensão da dinâmica da resistência bacteriana e para estratégias de consumo. Estudo preliminar ${ }^{1}$ do Projeto EUREQA (Epidemiologia do Uso e da Resistência Bacteriana a Quimioterápicos e Antibióticos na População. http://www.dpi.inpe.br/eureqa, acessado em 12/Set/2009) investigou processos de construção da resistência bacteriana aos antimicrobianos na população em geral. Tal estudo, realizado em São Paulo, utilizou estratégia analítica espaço-temporal, baseado na correlação entre consumo populacional de ciprofloxacina, mensurado por auditoria de venda, e ocorrência de resistência em Escherichia coli de infecções urinárias (ITUs) comunitárias . Nesse estudo, padrões de distribuição urbana da resistência em $E$. coli associaram-se à maior densidade de consumo de ciprofloxacina, estabelecendo o consumo populacional de antimicrobianos como fator desencadeador de pressão seletiva de resistência.

Esta nota expande a análise descrita para correlação entre consumo de antimicrobianos da classe das quinolonas (ácido nalidíxico, ciprofloxacina, levofloxacina e norfloxacina) e resistência em $E$. coli comunitárias. Uma vez estabelecida a correlação entre padrão de consumo de anti- 
microbianos e surgimento de resistência, podese propor critérios para exploração de dados de receituário médico controlado que permitam maior compreensão da dinâmica das resistências comunitárias com vistas a estabelecimento de medidas de saúde pública.

\section{Material e métodos}

A área de estudo refere-se à Cidade de São Paulo e os dados empregados são do banco de dados do EUREQA-SP, 2002 a 2007, contendo: (i) bases de dados geográficas; (ii) dados adquiridos de duas unidades laboratoriais de grande porte (privada e pública), com resultados positivos de urocultura para E. coli representativas de ITUs comunitárias. Considerados eventos pontuais mapeados sobre área de estudo, os dados foram categorizados como resistentes $(R)$ quando antibiograma com não susceptibilidade a qualquer das quinolonas, ou sensíveis $(S)$ quando antibiograma sensível; (iii) dados de consumo das quinolonas obtidos por auditoria de mercado sobre pontos de vendas da área de estudo (IMS Health Brazil). Para cada ponto de venda gerou-se informação de DDD (defined daly dose) 2 mensal - média estimada da dose de manutenção do medicamento em sua principal indicação para adultos; (iv) zonas de influência (ZI) construídas com base em cada ponto de venda, conforme Kiffer et al. ${ }^{1}$. Cada ZI (Figura 1) contém certa quantidade de eventos $R$ e $S$, e também densidades de DDD expressas como:

D_DDDA $_{k, t}=\frac{\mathrm{DDDA}_{k, t}}{\left(\frac{\mathrm{Pop}_{k}}{1000}\right) * 30}$,

em que: $D_{D D A}$ é a média de DDD cumulativa de três meses na $k$-iésima ZI e para o $t$-iésimo mês $(t=1,2, \ldots, 12), \operatorname{Pop}_{k} / 1000$ é a população estimada por 1.000 habitantes restrita à $k$-iésima ZI e 30 é o número de dias do mês.

Então, cada evento $R$ ou $S$ restrito a uma ZI está exposto ao respectivo valor de D_DDDA $k, t$, de acordo com a data de ocorrência.

O modelo empregado ${ }^{1}$ adota abordagem semiparamétrica. Trata-se de Modelo Aditivo Generalizado (GAM) ${ }^{3}$ adaptado, permitindo relacionar o consumo de antimicrobianos (D_DDDA $k$, com resistência em $E$. coli e posteriormente estimar o risco da resistência sobre a área de estudo. O modelo:

$\log \left[\frac{p(s)}{1-p(s)}\right]=\beta_{0}+\beta_{1}$ D_DDDA $+\beta_{2} \mathrm{I}_{1}+\beta_{3} \mathrm{I}_{2}+g(s)$,

em que: $\log [p(s) / 1-p(s)]$ é a estimativa do logaritmo do risco de resistência de E. coli na localiza- ção $s$; $\beta_{0}$ é o intercepto do modelo de regressão; $\beta_{1}, \beta_{2}$, e $\beta_{3}$ são os efeitos das covariáveis; $I_{1}=1$ se $\mathrm{T}_{1}<\mathrm{D} \_\mathrm{DDDA}<\mathrm{T} 2$ e $\mathrm{I}_{1}=0$ caso contrário; $\mathrm{I}_{2}=1$ se D_DDDA $>\mathrm{T}_{2}$ e $\mathrm{I}_{2}=0$ caso contrário; $\mathrm{T}_{1}$ e $\mathrm{T}_{2}$ são pontos de mudança de resistência de $E$. coli (Figura 2), identificados após a realização de uma análise inicial dos dados pela montagem de um modelo de regressão logística ordinário sem o termo espacial $g(s)$, mas permitindo um efeito aditivo (suave) de D_DDDA sobre o risco de resistência bacteriana por E. coli; e $g(s)$ é uma função suave estimada nas coordenadas espaciais $s$. Se o risco é assumido constantemente, então $g(s)=$ 0 e o modelo se reduz a um modelo de regressão logística usual 4.

\section{Resultados}

A Figura 2 mostra que o risco de resistência em $E$. coli, em 2002, ocorreu com o nível de consumo de quinolonas na população da ordem de 8 a 28 DDDA/1.000 habitantes/dia.

Constatou-se também que a média de consumo de quinolonas estava relacionada com focos de riscos de resistência distribuídos pela cidade. Para tal, o teste global da hipótese nula de risco não variável espacialmente e a identificação de focos de baixo e alto riscos foram feitos empregando-se o método de simulação de Monte Carlo ${ }^{5}$. O teste global apontou para uma variação espacial do risco significativa (valor de $p=0,0023$ ). A Figura 3 apresenta focos de baixo e alto riscos, para um nível de $95 \%$ de confiança, com contornos de tolerância de 2,5\% e 97,5\%, respectivamente.

Adicionalmente, executou-se análise de sensibilidade, e a correlação entre os efeitos espaciais e os coeficientes de regressão para covariáveis variando espacialmente não foi relevante para a análise destes dados. Um modelo aditivo generalizado permitindo uma função suave de D_DDDA juntamente com um efeito espacial foi também aplicado (linha sólida da Figura 2), e os resultados mantiveram suas significâncias no nível de $5 \%$. Além disso, o modelo empregado apresentou ajuste comparável com o modelo GAM, sendo escolhido para o presente estudo devido à sua interpretação mais clara.

\section{Discussão}

O atual projeto baseou-se em conceito ecológico de desenvolvimento da resistência a antimicrobianos 1 . Tal conceito considera que diferentes determinantes epidemiológicos podem favorecer a emergência de resistência em certos 

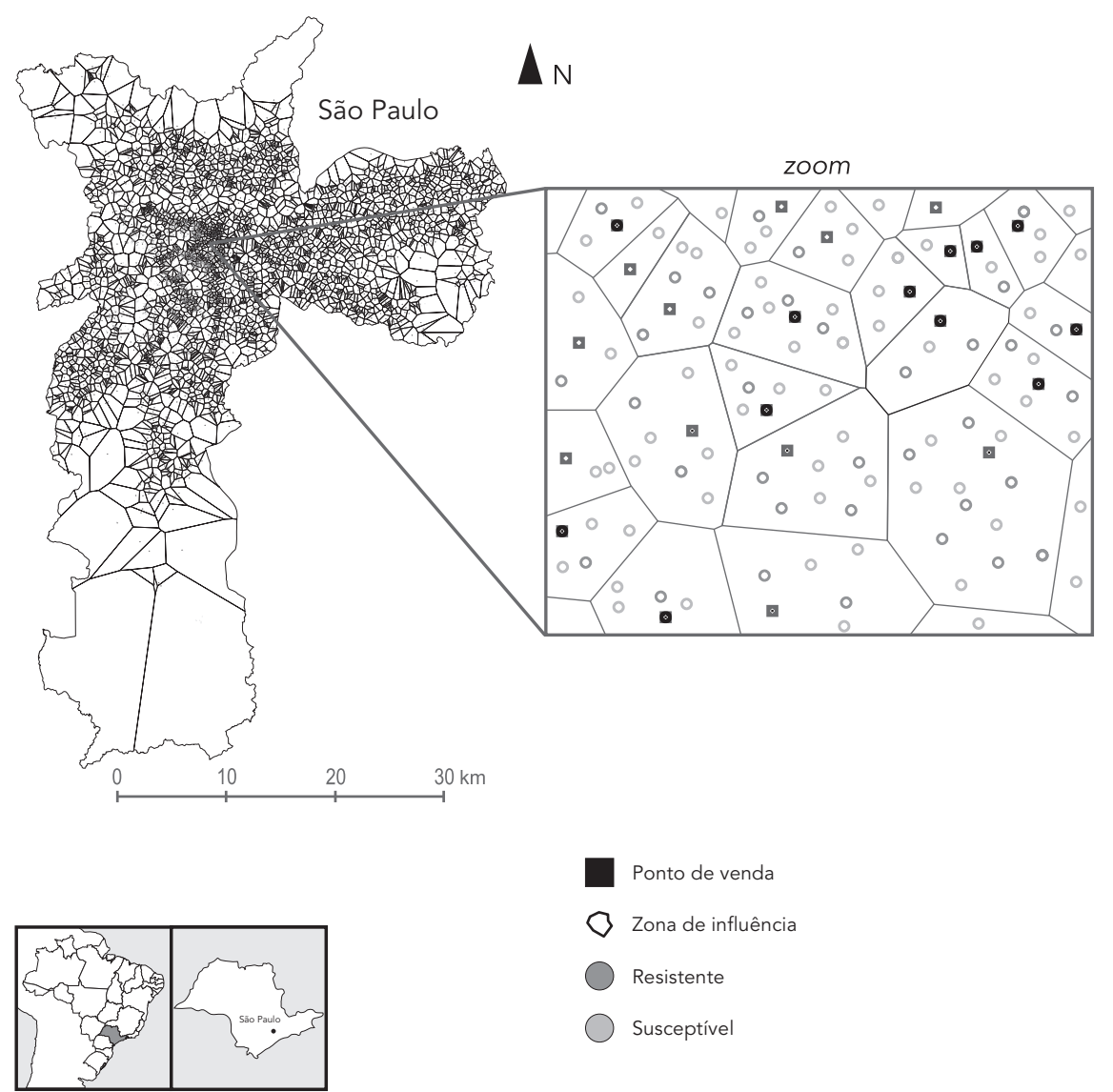

Ponto de venda
Zona de influência
Resistente
Susceptível

ambientes 6,7. Portanto, a hipótese básica do Projeto EUREQA considerou que maiores concentrações de consumo de antimicrobianos em dados ecossistemas (atual exemplo, uma cidade) estejam relacionados ao surgimento da resistência e a eventuais alterações nas populações microbianas ${ }^{8}$. Para investigar tais fatos, o projeto propôs modelo espaço-temporal ${ }^{1} \mathrm{com}$ a finalidade de correlacionar o consumo de antimicrobianos e ocorrência de resistência comunitária.

Com base nesse modelo, detectou-se que níveis de consumo das quatro quinolonas agregadas entre 8 e 28 D_DDDAs/1.000 habitantes/dia teve relação com o surgimento de resistência e a agregados espaciais de resistência em E. coli. Ou seja, em uma população de 1.000 habitantes por dia na cidade de São Paulo, entre 8 e 28 indivíduos consumindo dose média de adultos de qualquer das quatro quinolonas em áreas próxi- mas está relacionado a maior risco de resistência a estes antimicrobianos nas E. coli de ITUs comunitárias, independentemente do consumo individual. Esse achado demonstra de forma quantitativa a correlação entre consumo humano populacional de antimicrobianos e resistência bacteriana individual. Ou seja, aumentos de concentração de antimicrobianos na população humana de uma cidade estão correlacionados ao surgimento de resistência individual e a alterações na população microbiana daquela zona de influência.

Porém, além de demonstrar a importância da informação sobre o consumo de antimicrobianos, o atual artigo propõe estratégias de saúde pública que tenham como base análises quantitativas de eventos reais. Dessa forma, o modelo proposto pode fornecer uma moldura operacional que permita o teste de hipóteses de efeitos 


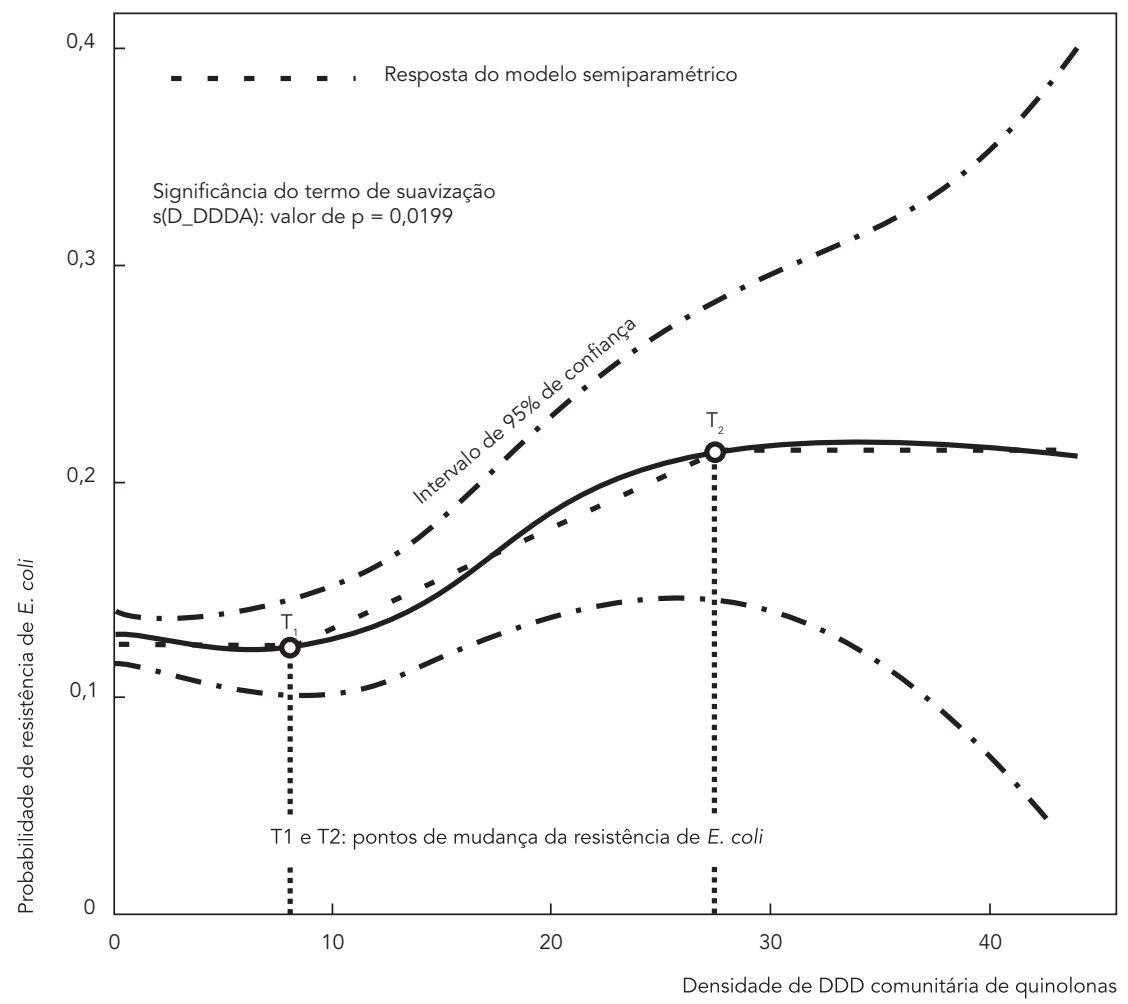

indiretos de prescrições ou de consumo sobre a resistência a antimicrobianos.

Embora os medicamentos antimicrobianos de uso comunitário (de vendas em farmácias e drogarias) tenham sempre sido sujeitos à prescrição médica, até recentemente não havia a obrigatoriedade de retenção de receitas. Logo, tornava-se difícil executar medidas de controle e análise sobre padrões prescritivos ou consumo de antimicrobianos e suas implicações.

Isso mudou a partir de outubro de 2010, quando a Agência Nacional de Vigilância Sanitária (ANVISA) estabeleceu a Resolução da Diretoria Colegiada $n^{o} .449$ (RDC 44/2010) com procedimentos relativos ao controle de medicamentos à base de substâncias classificadas como antimicrobianos, de uso sob prescrição médica, isoladas ou em associação. A RDC 44/2010 estabelece que o receituário simples, prescrito em duas vias com determinadas informações exigidas, precisará ser aviada, não sendo reutilizada para compras posteriores, e ficará retida nas farmácias e drogarias. Além disso, esses estabelecimentos passam a ter obrigação de escriturar a movimentação dos medicamentos que contenham substâncias antimicrobianas (anexo da RDC 44/2010). Muito embora a retenção de receitas deva ter impacto potencial na redução global de consumo de antimicrobianos, o que precisa ser avaliado é a correlação entre consumo e resistência, fornecida pelo atual modelo, pois, da mesma forma que observamos correlação positiva entre consumo das quinolonas e resistência comunitária em E. coli, é possível que haja outras correlações com diferentes antimicrobianos ou classes.

A RDC 44/2010 oferece oportunidade para auxiliar nessas políticas de saúde com antimicrobianos baseada em novo conjunto de dados. Esses dados possibilitam a utilização de métodos analíticos que introduzem o espaço como categoria analítica, conforme o atual estudo. Dessa forma, seria possível estruturar um Sistema $\mathrm{Na}$ cional de Informação de Consumo de Antimicro- 


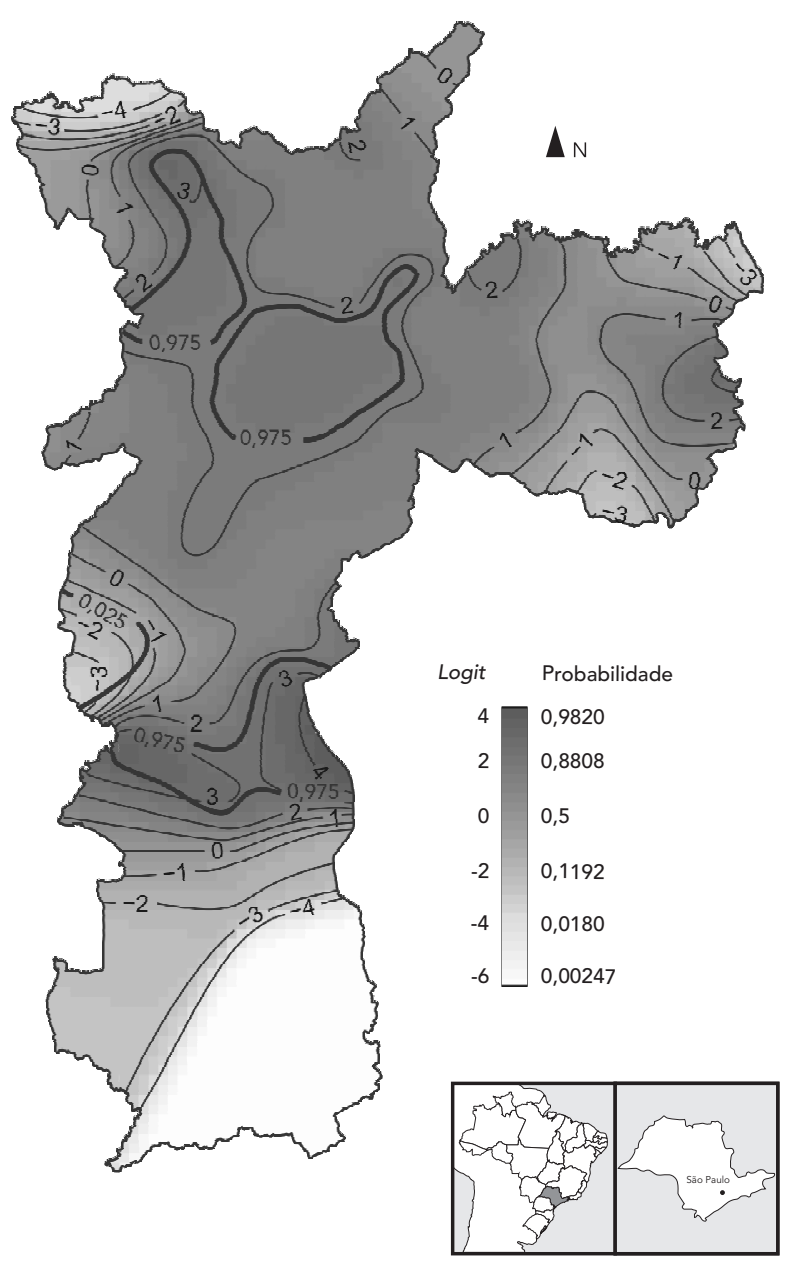

bianos, concebido com base em Banco de Dados Geográfico (BDG) nacional, com informações sobre a localização dos pontos de venda e a quantidade de antimicrobianos prescritos ou vendidos. Esse BDG poderia ser usado para análises frente a perfis locais de resistência ou de outros fatores populacionais, permitindo medidas estratégicas interventivas em saúde pública, como estímu- lo ou restrição de uso de determinados antimicrobianos. O Projeto EUREQA demonstrou ser tecnologicamente possível construir esse BDG. Em escala nacional, adaptações provavelmente seriam necessárias e novos desafios surgiriam, mas não haveria dificuldades maiores para implantação deste projeto, baseado em tecnologias, protocolos e padrões abertos. 


\section{Resumo}

A presente nota pesquisa demonstra que o uso das informações de receituário ou prescrição médica tem fundamental valor para a compreensão das correlações da dinâmica da resistência bacteriana comunitária. Além disso, a análise dos dados gerada pode ajudar a estabelecer medidas e políticas de saúde pública mais adequadas para o controle e a otimização do consumo de antimicrobianos. Para isso, o artigo usa como base o modelo lógico desenvolvido pelo Projeto EUREQA voltado para aquisição, classificação, interpretação e análise das informações relacionadas à prescrição dos antimicrobianos de uso oral.

Prescrições de Medicamentos; Antibacterianos; Resistência Microbiana a Medicamentos

\section{Colaboradores}

E. C. G. Camargo coletou, padronizou o banco de dados, revisou criticamente o experimento, realizou as análises e escreveu o artigo. C. R. V. Kiffer delineou, coletou, realizou parte das análises, revisou criticamente os experimentos e escreveu o artigo. A. C. C. Pignatari revisou criticamente o experimento, analisou, interpretou e revisou criticamente os dados microbiológicos. S. E. Shimakura revisou o experimento, auxiliou no desenvolvimento do modelo, analisou, interpretou e revisou criticamente os dados estatísticos. P. J. Ribeiro Jr. revisou o experimento, auxiliou no desenvolvimento do modelo, analisou, interpretou e revisou criticamente os dados estatísticos. A. M. V. Monteiro coordenou, delineou, supervisionou a coleta de dados, revisou os dados, realizou parte das análises e escreveu o artigo. Todos os autores aprovaram a versão final a ser publicada.

\section{Agradecimentos}

Trevor Bailey pela proposta do modelo analítico. À Fundação de Amparo à Pesquisa do Estado de São Paulo (FAPESP) pelo auxílio para realização do projeto. Ao Hospital São Paulo, Escola Paulista de Medicina, Universidade Federal de São Paulo (EPM-UNIFESP) e ao Instituto Fleury pelo fornecimento dos dados microbiológicos para o desenvolvimento da pesquisa.

\section{Referências}

1. Kiffer CRV, Camargo ECG, Shimakura SE, Ribeiro Jr. PJ, Bailey TC, Pignatari ACC, et al. A spatial approach for the epidemiology of antibiotic use and resistance in community-based studies: the emergence of urban clusters of Escherichia coli quinolone resistance in Sao Paulo, Brasil. Int J Health Geogr 2011; 10:17.

2. World Health Organization Collaborating Centre for Drug Statistics Methodology. Anatomical therapeutic chemical (ATC) index with defined daily doses (DDDs). http://www.whocc.no/atcddd (acessado em 06/Ago/2009).

3. Hastie T, Tibshirani R. Generalized additive models. London/New York: Chapman and Hall; 1990.

4. Hosmer DW, Lemeshow S. Applied logistic regression. New York: Wiley; 1989.

5. Kelsall JE, Diggle PJ. Spatial variation in risk of disease: a nonparametric binary regression approach. J R Stat Soc Ser C Appl Stat 1998; 47:559-73.

6. Harbarth S, Samore MH. Antimicrobial resistance determinants and future control. Emerg Infect Dis 2005; 11:794-801.

7. Manges AR, Johnson JR, Foxman B, O'Bryan TT, Fullerton KE, Riley LW. Widespread distribution of urinary tract infections caused by a multidrug-resistant Escherichia coli clonal group. N Engl J Med 2001; 345:1007-13.

8. Martinez JL. Antibiotics and antibiotic resistance genes in natural environments. Science 2008; 321:365-7.

9. Agência Nacional de Vigilância Sanitária. Resolução da Diretoria Colegiada - RDC no ${ }^{\circ}$ 44, de 26 de outubro de 2010. Dispõe sobre o controle de medicamentos à base de substâncias classificadas como antimicrobianos, de uso sob prescrição médica, isoladas ou em associação e dá outras providências. Diário Oficial da União 2010; 27 out.

Recebido em 13/Set/2011

Versão final reapresentada em 13/Fev/2012 Aprovado em 16/Fev/2012 